\title{
The letter height superiority illusion
}

\author{
Boris New • Karine Doré-Mazars • Céline Cavézian • \\ Christophe Pallier • Julien Barra
}

Published online: 14 September 2015

(C) Psychonomic Society, Inc. 2014

\begin{abstract}
Letters are identified better when they are embedded within words rather than within pseudowords, a phenomenon known as the word superiority effect (Reicher in Journal of Experimental Psychology, 81, 275-280, 1969). This effect is, inter alia, accounted for by the interactive-activation model (McClelland \& Rumelhart in Psychological Review, 88, 375$407,1981)$ through feedback from word to letter nodes. In this study, we investigated whether overactivation of features could lead to perceptual bias, wherein letters would be perceived as being taller than pseudoletters, or words would be perceived as being taller than pseudowords. In two experiments, we investigated the effects of letter and lexical status on the perception of size. Participants who had to compare the heights of letters and pseudoletters, or of words and pseudowords, indeed perceived the former stimuli as being taller than the latter. Possible alternative interpretations of this height superiority effect for letters and words are discussed.
\end{abstract}

Keywords Visual word recognition · Reading $\cdot$ Visual illusion · Interactive activation model · Perceptual fluency · Backpropagation

B. New $(\bowtie)$

Université de Savoie, LPNC, F-7300 Chambéry, France

e-mail: boris.new@univ-savoie.fr

K. Doré-Mazars $\cdot$ J. Barra

Laboratoire Vision Action Cognition EA7326, Université Paris Descartes, Sorbonne, Paris Cité, France

K. Doré-Mazars

Institut Universitaire de France, Paris, France

C. Cavézian · C. Pallier

INSERM-CEA Cognitive Neuroimaging Unit, Neurospin Center,

Gif-sur-Yvette, France
Learning how to read entails modifications in the vision and language neural networks, leading to phenomena such as the word superiority effect. In the present study, we report on the discovery that letters and words are perceived to be taller than matched pseudoletters or reversed-syllable words (respectively), demonstrating that the processing of letters or words can have low-level perceptual consequences.

The word superiority effect was discovered by Reicher (1969), who observed that letters are easier to identify when presented within a word rather than in a nonword (an illegal letter sequence) or in isolation. Interestingly, this effect has been generalized to letter fragments, which are easier to identify when they are presented in a letter than when they are in isolation (the letter superiority effect: Schendel \& Shaw, 1976). Besides, Reingold and Jolicour (1993) showed that the color of a fragment is perceived more accurately in letter than in nonletter contexts. Similar effects have also been observed with nonverbal stimuli such as objects. For instance, a line segment is more accurately identified when it is part of a drawing that lookw unitary than when it is part of a less coherent drawing (Weisstein \& Harris, 1974; Williams \& Weisstein, 1978). These effects can be explained either by topdown modulations during the early stages of visual processing or by the fluency hypothesis account, according to which stimuli that are perceived more fluently are more likely to be easier to recognize.

The interactive-activation model (IAM) of McClelland and Rumelhart (1981) has been proposed as an explanation of the letter and word superiority effects. This connectionist model assumes three levels or representations: a low level representing features, an intermediate "letter" level, and an upper "word" level. When a visual stimulus is presented, activation propagates from the lower level to the higher ones. The word or letter superiority effects are explained by rapid 
back-propagation of activation from higher levels (word or letter) to lower ones (letter or feature). Thus, the activation of lower-level units is boosted when items are presented in an existing context rather than in isolation. Notwithstanding, the multiple-read-out-level model (Grainger \& Jacobs, 1996) proposed that the word superiority effect can be obtained in the absence of top-down processes. More specifically, in specific experimental conditions, the correct response can be generated from several (instead of one) codes. The correct choice between letters presented in a briefly displayed word stimulus can be generated either by the activation of the correct letter representation or by the activation of the appropriate word representation.

Other studies have shown top-down effects on perception. For instance Lupyan, Thompson-Schill, and Swingley (2010) asked participants to judge physical identity on visually equidistant pairs of letter stimuli that were either in the same conceptual category $(\mathrm{Bb})$ or in different categories (Bp). The authors showed that participants were faster to judge physical identity when stimuli were in different categories than when they were in the same one. The authors explained this as an example showing that the knowledge of a category, here the letter identity, can influence visual perception. It has also been shown that memory influences perception. For instance, objects associated with a typical color tended to be perceived in this color (Olkkonen, Hansen, \& Gegenfurtner, 2008).

In the present study, we focused on the perception of letters' heights in comparison to the perception of pseudoletters' heights. In the framework of the IAM, we wondered whether increased activation of features units would modulate the perception of stimulus size. This could be predicted by the IAM if we postulated that the more that feature units are activated, the taller the stimulus appears. For instance, letters would be perceived as taller than pseudoletters, since the feature units would benefit from back-propagation from the letter level. Furthermore a similar hypothesis could be drawn for words. Indeed, a word should be perceived as taller than a nonword made of pseudoletters, since the feature units would benefit from back-propagation from both the letter and word levels. The IAM model also predicts that the illusion should be stronger for words than for letters, since back-propagation would come from two levels for words (i.e., letter and word units), but only from one level for letters (letter units).

In order to test these hypotheses, we used a size comparison task in which participants had to decide whether two stimuli, one letter and one pseudoletter or mirror letter, were of identical or different heights (Exp. 1). In Experiment 2, we examined the size comparison task with words, nonwords, mirror words, and reversed-syllable words.

\section{Experiment 1 (letters)}

Method

Participants A group of 24 participants (seven men and 17 women, $22 \pm 6$ years old; four left-handed and 20 righthanded), students at Descartes University in Paris, participated for course credit. All of the participants reported normal or corrected-to-normal vision and were native speaker of French.

Stimuli and design The stimuli were nine lowercase letters in Times New Roman font (i.e., $a, c, e, m, r, s, v, w, z$ ), nine mirror letters, and nine pseudoletters. The mirror letters were constructed from the original letters using a vertical mirror symmetry transformation (see the Appendix). The pseudoletters were constructed to match the letters' physical properties (height, number of pixels, and contiguous pixels) by reconfiguring the features of the original letter. For each of these 27 stimuli, two different sizes were created, the small one taking up $0.28^{\circ}$ of vertical angle (horizontal angle: $0.29^{\circ}$ ) and the taller one $0.30^{\circ}$ of vertical angle (horizontal angle: $0.32^{\circ}$ ). We used three types of stimuli: letters, mirror letters, and pseudoletters. The vertical mirror letters were included in order to have stimuli with spatial properties as similar as possible to those of the letters.

Participants were seated in front of a 17 -in. monitor $(1,024$ $\times 768$ pixels, $85 \mathrm{~Hz}$ ); their heads were stabilized with a chinrest, $64 \mathrm{~cm}$ away from the screen. A trial started with the presentation of a central fixation cross for $200 \mathrm{~ms}$, followed by the simultaneous display of two horizontally aligned stimuli $\left(2.75^{\circ}\right.$ to the right and the left of the center) for $700 \mathrm{~ms}$. Finally, a white screen was presented until the participant responded. One of the two stimuli was always a letter; the other one could be a letter, a mirror letter, or a pseudoletter (see Fig. 1a). Participants were asked to compare the heights of the stimuli. When they judged the two stimuli to be identical, they had to press with their dominant hand the down arrow on the keyboard, and when they judged one stimulus was taller than the other one, they indicated its position with the left or the right arrow. The next trial began $750 \mathrm{~ms}$ after the response of the participant.

On half of the trials, the stimuli were of the same height (same-height trials; Fig. 1b), whereas on the other half they were of different heights (different-height condition; Fig. 1c). Mixed with the types of the pairs of stimuli, this led to eight experimental conditions: letter $=$ letter, letter $=$ pseudoletter, letter $=$ mirror letter, letter $>$ letter, letter $>$ pseudoletter, letter $>$ mirror letter, letter $<$ pseudoletter, and letter $<$ mirror letter. The positions of the letter and of the other stimulus (in the right and left parts of the screen) were counterbalanced. Each participant received a different, randomized order of trials. The experimental session included 216 trials, repeated three times, and lasted about $45 \mathrm{~min}$. Every 108 trials, the participants were offered a short 
(a) Examples of the presented pairs of stimuli having the same objective height

(b) Same physical height

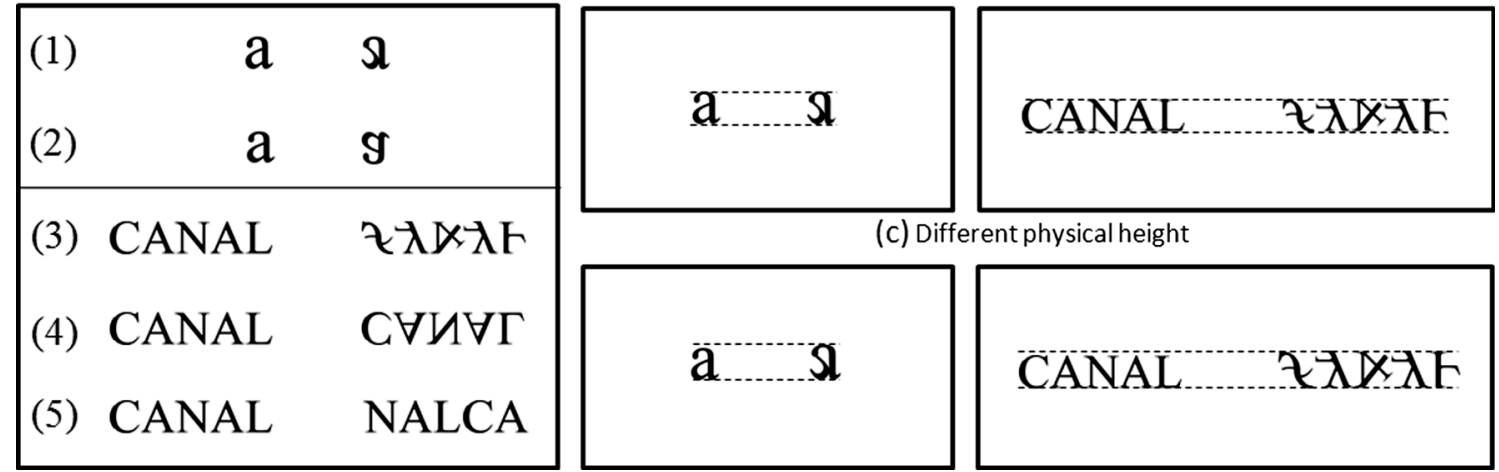

Fig. 1 (a) Examples of the pairs of stimuli used in Experiments 1 and 2: (1) letter-pseudoletter (2) letter-mirror letter, (3) word-nonword, (4) word-mirror word, and (5) word-reversed-syllable word. (b) Example

break. Before beginning the experiment, participants completed a training session until they reached $80 \%$ correct responses. This session included 12 different stimulus configurations using three letters $(u, n$, and $x)$ not presented in the experimental session. In the training session, feedback was displayed after each trial, and only letters were used in order to achieve the $80 \%$ criterion.

\section{Results}

Percentages of errors were analyzed using repeated measures analyses of variance (ANOVAs). Overall, participants made $32.7 \%$ errors throughout the experiment $(36.5 \%$ in the sameobjective-height condition vs. $28.9 \%$ in the differentobjective-height condition) $[F(1,23)=3.44, p=.077]$. Whatever the experimental conditions (same or different objective heights), the percentage of errors depended on the type of pairs presented $\left[F(2,46)=339.76, p<.001, \eta^{2}=.94\right]$ : The pairs of two letters produced fewer errors than did the pairs composed of a letter and another stimulus (pseudoletter or mirror letter) $[19.1 \%$ and $39.4 \%$, respectively; $F(1,23)$ $=12.3, p<.01]$.

Separate statistical analyses were performed on the conditions in which both stimuli had the same objective size and the condition in which both stimuli were of different sizes.

Same-objective-height condition When the pair of stimuli of the same objective height consisted of a letter and another type of stimulus (Fig. 2a), the letter was more often chosen as the tallest stimulus [letter-pseudoletter pair: $82.8 \%$ vs. $17.2 \%, F(1,23)=91.47, p<.001, \eta^{2}=.80$; letter-mirrorletter pair: $60.5 \%$ vs. $39.5 \%, F(1,23)=8.92, p<.01, \eta^{2}$ $=.38]$. This bias favoring the letter was stronger for the comparison with the pseudoletter than for the one with the mirror letter $[82.8 \%$ vs. $60.5 \%, F(1,23)=65.68, p<$ $\left..001, \eta^{2}=.74\right]$. of pairs having the same physical height. (c) Example of pairs having different physical heights. The dashed lines did not appear on the screen during the experiment

These results suggest that a letter's height was overestimated when it was compared to other stimuli of the same objective height.

Different-objective-height conditions The percentage of errors when the letter and the other stimulus had different heights (Fig. 2b) was greater when the letter was smaller than when it was taller than the pseudoletter $(75.9 \%$ vs. $31.9 \%)$ $\left[F(1,23)=83.31, p<.001, \eta^{2}=.78\right]$ or the mirror letter $(40.1 \%$ vs. $31 \%)\left[F(1,23)=13.87, p<.01, \eta^{2}=.38\right]$. Whatever the type of the pair of stimuli, the most frequent error was to perceive the two stimuli as having an identical size $(88.8 \%$ of errors).

In summary, Experiment 1 showed that when letters and pseudoletters had the same objective height, the letters were perceived to be taller. Furthermore, when letters were smaller than letters, participants perceived that the two stimuli had the same height. The next question was whether a similar pattern of effects could occur with words. In order to address the specificity of lexical (word) influences, we created nonwords made of reversed syllables. Thus, these nonwords contained the same syllables as the words and shared most of their open bigrams. Furthermore, in order to check that the effect in Experiment 1 could be extended to the word level, we created nonwords (made of pseudoletters) and vertical mirror of words and used them in the same procedure as in the first experiment.

\section{Experiment 2 (words)}

Method

Participants A group of 24 new participants (eight men and 16 women, $20.4 \pm 2$ years old; five left-handed and 19 righthanded) from Paris Descartes University participated in the 


\section{(a) Same objective height}

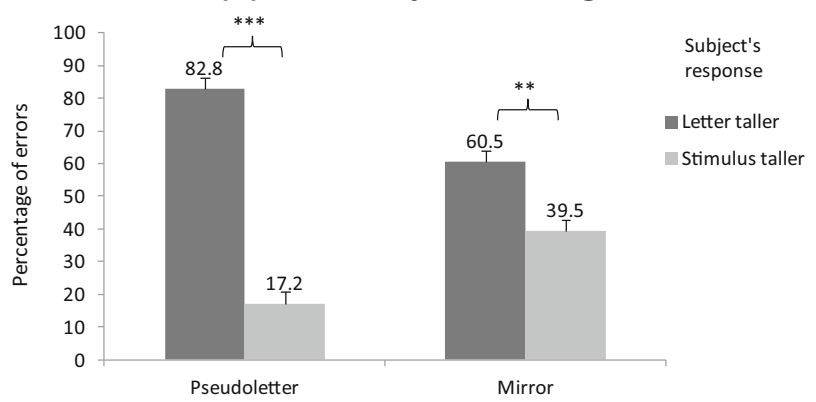

Fig. 2 Distribution of the percentages of errors, as a function of the stimulus type (pseudoletter or mirror) to be compared to the letter, in the (a) same-objective-height and (b) different-objective-height conditions. For instance, in the same-objective-height condition for pseudoletters, we compared the percentage of answers that the letter was taller with the

experiment for course credit. All of the participants reported normal or corrected-to-normal vision and were native speaker of French.

Material Nine uppercase French words (BATEAU, BUREAU, CAMION, CANAL, GENOU, JARDIN, LAPIN, PARFUM, and TUYAU) in Times New Roman font were used to create mirror words, nonwords, and pseudowords made of reversed syllables (see the Appendix). These nine words had an average subtitle lemma frequency of 64 occurrences per million. They were all common, concrete nouns having two syllables, five- or six-letter lengths, and no accentuated characters. The nine mirror words were constructed using a vertical mirror symmetry transformation of the word (see Fig. 1). The reversed-syllable pseudowords were composed of the reversed order of the syllables from the original word (e.g., NALCA for CANAL). We checked that these pseudowords respected French phonotactic rules. The pseudoletters of the nonwords were constructed to have physical properties similar to those of the word letters by reconfiguring the letters' line forms, and they were precisely matched for height, width, and pixel number (see the Appendix). Consequently, each nonword's width, height, and pixel number was always matched with its associated word stimulus.

For each of the 36 stimuli (nine words, nine mirror words, nine reversed-syllable pseudowords, and nine nonwords made of pseudoletters), two versions of different sizes were created, one taking up $0.4^{\circ}$ of vertical angle (horizontal angle: $2.04^{\circ}$ ), and the other taking up $0.44^{\circ}$ of vertical angle (horizontal angle: $2.24^{\circ}$ ). On half of the trials, the stimuli were of the same height (same-height trials; Fig. 1b), whereas on the other half they were of different heights (different-height condition; Fig. 1c). Mixed with the types of the pairs of stimuli, this led to 11 experimental conditions: word $=$ word, word $=$ mirror word, word $=$ reversed-syllable pseudowords, word $=$ nonword, word $>$ word, word $>$ mirror word, word $>$ reversed-

\section{(b) Different objective heights}

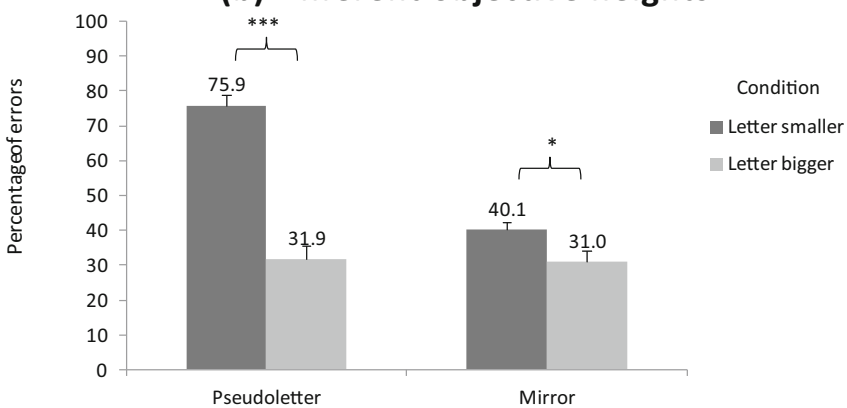

percentage of answers that the pseudoletter was taller. In the differentobjective-height condition, we compared the percentages of errors in the "letter smaller than pseudoletter" and "letter bigger than pseudoletter" experimental conditions. The asterisks indicate significant differences: ${ }^{*} p$ $<.05,{ }^{* *} p<.01,{ }^{* * *} p<.001$. Error bars represent standard errors

syllable pseudoword, word $>$ nonword, word $<$ mirror word, word $<$ reversed-syllable pseudoword, and word $<$ nonword. The positions of the word and the other stimulus (in the right and left parts of the screen) were counterbalanced. Each participant received a different, randomized order of trials.

The experiment included 288 trials, repeated three times, and lasted about $45 \mathrm{~min}$. After every 144 trials, the participants were offered a short break. Before beginning the experiment, participants were run in a training session until they reached $80 \%$ correct responses. This session included 12 different stimulus configurations based on three words (RADIO, PAPIER, and MAISON) not presented in the experimental session. In the training session, feedback was displayed after each trial, and only words were used in order to achieve the $80 \%$ criterion.

Stimuli and design Participants were seated $64 \mathrm{~cm}$ away from a 17-in. monitor $(1,024 \times 768$ pixels, $85 \mathrm{~Hz})$; their heads were stabilized with a chinrest. First, a central fixation cross was presented for $200 \mathrm{~ms}$. Then two aligned stimuli were simultaneously presented for $500 \mathrm{~ms}$, one on each side of the center $\left(0.9^{\circ}\right.$ of eccentricity), and followed by a white screen (until the participant responded). One of the two stimuli was always a word, whereas the other one could be a word, a mirror word, a pseudoword (reversed syllables), or a nonword (made of pseudoletters). As in Experiment 1, participants were asked to compare the heights of the two stimuli. When they judged the two stimuli to be identical, they pressed with their dominant hand the down arrow on the keyboard, and when they judged one stimulus to be taller than the other one, they indicated its position with the left or the right arrow. The next trial began only when the participant had given a response.

Results

The percentages of errors were analyzed using ANOVAs (see Fig. 3). On average, participants made $25.2 \%$ 


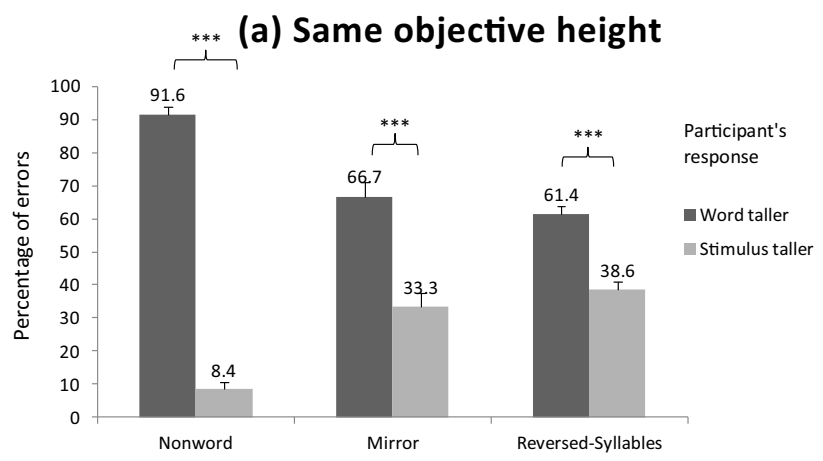

Fig. 3 Distribution of the percentages of errors, as a function of the stimulus type (nonword, mirror word, or reversed-syllable pseudoword) to be compared to the word, in the (a) same-objective-height and (b) different-objective-height conditions. For instance, in the same-objectiveheight condition for nonwords, we compared the percentage of answers that the word was taller with the percentage of answers that the nonword

errors throughout the experiment $(27.8 \%$ in the sameobjective-height condition vs. $22.6 \%$ in the differentobjective-height condition). Whatever the experimental condition (same or different objective heights), the percentage of errors depended on the type of pair presented $\left[F(3,69)=102.96, p<.001, \eta^{2}=.82\right]$. Indeed, the pairs consisting of two words produced fewer errors than did the pairs composed of a word and another stimulus (nonword, mirror word, or pseudoword) $\left[16.4 \%\right.$ vs. $26.9 \%, F(1,23)=66.57, p<.001, \eta^{2}=$ .73].

Separate statistical analyses were performed on the conditions in which both stimuli had the same size (identical) and in which both stimuli were of different sizes.

Same-objective-height condition When the pair of stimuli consisted of a word and another type of stimulus (nonword, mirror word, or reversed-syllable stimulus), the word was more often chosen as the tallest stimulus [word-nonword pairs: $91.6 \%$ vs. $8.4 \%, F(1,23)=381.1, p<.001, \eta^{2}=$ .94 ; word-mirror-word pairs: $66.7 \%$ vs. $33.3 \%, F(1,23)=$ 14.71, $p<.001, \eta^{2}=.39$; word-reversed-syllable pairs: $61.4 \%$ vs. $\left.38.6 \%, F(1,23)=19.54, p<.001, \eta^{2}=.45\right]$. This bias favoring words was stronger for the comparison with the nonword than for the comparison with the mirror word $\left[91.6 \%\right.$ vs. $\left.66.7 \%, F(1,23)=32.48, p<.001, \eta^{2}=.58\right]$. The pair of stimuli including a mirror word did not lead to more errors than did the pair of stimuli including a reversedsyllable pseudoword $[66.7 \%$ vs. $61.4 \%, F(1,23)=1.90, p=$ .18].

Different-objective-height conditions When a word was presented with another type of stimulus (nonword, mirror word, or reversed-syllable pseudoword), the percentage of errors was greater when the word was physically smaller than the other stimulus [word-nonword pairs: $73.1 \%$ vs. $20.7 \%, F(1$,

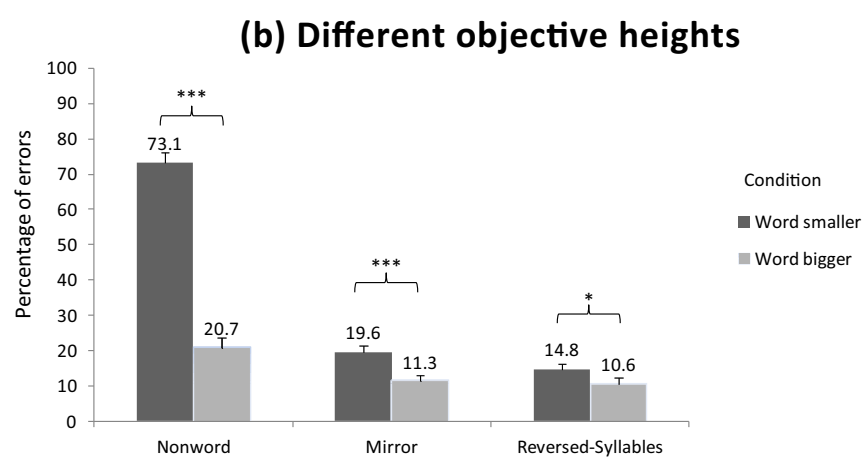

was taller. In the different-objective-height nonword condition, we compared the percentages of errors in the "word smaller than nonword" and "word taller than nonword" experimental conditions. The asterisks indicate significant differences: ${ }^{*} p<.05,{ }^{* * *} p<.001$. Error bars represent standard errors

23) $=132.48, p<.001, \eta^{2}=.58$; word-mirror-word pairs: $19.6 \%$ vs. $11.3 \%, F(1,23)=23.15, p<.001, \eta^{2}=.50$; wordreversed-syllable pairs: $14.8 \%$ vs. $10.6 \%, F(1,23)=7.30, p<$ $\left..05, \eta^{2}=.24\right]$. Whatever the type of the pairs, the most common error was to perceive both stimuli as having the same size ( $92.8 \%$ of the total number of errors). This result suggests that physically smaller words ware perceived as being taller than their objective height.

Comparison of the letter and word illusions Concerning letters, the IAM postulates that they will activate two different levels (the feature and letter levels) and that there will be back-propagation from the letter level to the feature level. Concerning words, the IAM postulates that three different levels will be activated (features, letters, and words) and that there will be back-propagation from the word and letter levels. Since words generate backpropagation from two levels and letters from only one, we assumed that our illusion should be stronger for words than for letters. We compared the intensities of the illusion for words and letters in the same-objectiveheight condition, since the illusions concerning letters and words were more directly comparable than in the "different-size" condition.

We ran a two-sample Student $t$ test to compare the percentages of errors in the letter-pseudoletter (of identical height) and the word-nonword (of identical height) conditions. The $t$ test revealed a significant difference between the two types of stimuli $[t(46)=2.19, p=$ .033 , Cohen's $d=0.64]$. This indicated that the illusion was stronger for words (which were perceived as being taller than nonwords in $91.6 \%$ of errors, although they were the same objective size) than for letters (which were perceived as being taller than pseudoletters in $82.8 \%$ of errors, although they were the same objective size). 


\section{Discussion}

In Experiment 1, when participants made errors they perceived letters as being taller than pseudoletters or mirror letters. First, when the two stimuli had the same height, participants judged the letter to be taller than the other stimulus. Second, when the letter was smaller than the other stimulus (pseudoletter or mirror letter), the participants reported that both stimuli had the same size (note that the percentage of errors was smaller in the reverse condition-i.e., when the pseudoletter or the mirror letter was smaller than the letter). These results suggest that letters were perceived as being taller than their objective size. Experiment 2 highlighted that this "misperception" could be extended to words, which were also perceived as being taller than their matched mirror stimuli, nonwords (composed of pseudoletters), or pseudowords (made by exchanging syllables). Furthermore, this height illusion was greater for words (and nonwords) than for letters (and pseudoletters).

Could the fact that letters and words are perceived as being taller than pseudostimuli or mirror stimuli result from a "perceptual" bias (i.e., the basic properties of the visual stimuli)? Although we attempted to control for numerous factors in the elaboration of the pseudoletters, it remained impossible to create a control stimulus that would share all of its features with a given letter. For this reason, we also used vertical mirror letters (or words). A potential problem of these controls was that the vertical distribution of pixels is not exactly the same as in the letter (or the word). One alternative could have been to use horizontal mirror letters. Yet, most children show spontaneous mirror-writing during their learning period of writing (Cornell, 1985). Moreover, it has been shown that humans and animals confuse lateral mirror images more often than vertical mirror images (see, e.g., Bornstein, Gross, \& Wolf, 1978, for experiments in four-month-old infants, and Rollenhagen \& Olson, 2000, for a study in monkeys). For these reasons, the use of vertical mirror stimuli seemed more appropriate. Nevertheless, further study should explore whether letters are also perceived as being taller than their horizontal mirror controls. Finally, the fact that words were also judged as being taller as reversed-syllable stimuli showed that this effect applied not only to the letter level, but also to the lexical (word) one. This result seemed to rule out an explanation based only on a bias resulting from basic properties of the visual stimuli.

At a theoretical level, these results fit well with both the perceptual-fluency hypothesis and the IAM, if we postulate that the more a unit coding for one feature is activated, the taller the feature would be perceived. In this model, words are recognized as a result of excitatory and inhibitory interactions between detectors from three levels: visual features, letters, and words. A visual input activates first the feature units, which then activate the compatible letter units, which in turn send activation to the compatible word units. Each level can send back activation (also called back-propagation) to the inferior levels. In the IAM, the letter height overestimation would result from the supplementary activation due to backpropagation from upper levels that would magnify the visual features. The very same mechanism could well explain the word height magnification. Nevertheless, a height magnification of the word was also observed in the word-pseudoword condition (e.g., CANAL vs. NALCA), in which both stimuli should have induced the same activation at the letter level (which should thus "cancel" the height overestimation of the word). This suggests that activation from the word level also contributed in this word height magnification.

Interestingly, recent imaging studies have shown evidence coherent with this view. First, it is now well established that half of the visual areas, including V1, V2, V3, and V4, are retinotopically mapped (Gattass, Sousa, \& Gross, 1988; Newsome, Maunsell, \& van Essen, 1986); that is, the neurons in the cortical area are organized to roughly preserve the structure of the retina (Kosslyn, 1994). For instance, Tootell, Silverman, Switkes, and De Valois (1982) trained a monkey to stare at a pattern. They then injected a radioactively tagged sugar. Finally, the animal was killed and the amount of radioactivity was measured. In V1, the first cortical area to receive input from the eyes, the drawing of radioactivity was clearly copying the pattern presented to the monkey. Regarding our study, this means that when we presented two stimuli of different sizes, the tallest one should have activated more neurons in V1. In a recent fMRI study, Szwed et al. (2011) compared written words to matched scrambled words. They observed stronger activations in areas V1/V2 and V3/V4 for words than for scrambled words. Such an increase in activation in early visual areas could possibly yield a perception of increased size due to the retinotopic structure of V1. Feedback from the word level to earlier visual-processing area is compatible with the fact that most visual areas are connected to several other visual areas through reciprocated connections (Rockland \& Pandya, 1979). This means that much information runs forward and backward among visual areas, and thus could modulate the processing of lower-level areas.

Madec, Rey, Dufau, Klein, and Grainger (2012) used a new method to track the time course of letter perception. Combining behavioral measures of letter identification time with event-related potential recordings, they found significant correlations around $220 \mathrm{~ms}$ at occipital electrode sites, which they interpreted as evidence for recurrent processing in primary visual areas.

Although the hypothesis described above seems attractive, an alternative explanation can be proposed. Indeed, our results are partly compatible with the perceptual-fluency hypothesis. According to this hypothesis, stimuli that are perceived more fluently are more likely to be easier to recognize, to be preferred, or to be estimated as being more frequent (Jacoby \& Dallas, 1981; Reber, Winkielman, \& Schwarz, 1998; Reber 
\& Zupanek, 2002; Waenke, Schwarz, \& Bless, 1995). Perceptual fluency can also modulate the perception of physical properties such as stimulus duration (Masson \& Caldwell, 1998), figure-ground contrast and clarity (Goldinger, Kleider, \& Shelley, 1999; Jacoby, Allan, Collins, \& Larwill, 1988; Whittlesea, Jacoby, \& Girard, 1990).

In the present experiments, since the letters and words were more familiar than the pseudoletters and nonwords, they might have been processed more fluently, leading to a magnification of the stimuli. Moreover, in this framework of perceptual fluency, Reber, Zimmermann, and Wurtz (2004) showed that words were perceived as being taller than nonwords made by rearranging letters into a pattern that did not correspond to German orthographic rules. Nevertheless, this hypothesis cannot account for the fact that our illusion was stronger for words than for letters. At least, if we speculate that isolated letters are processed similarly to letters presented inside words, then letters are more frequent than words. In this context, the fluency hypothesis cannot account for the fact that our illusion was stronger for words than for letters. Indeed if letters are more frequent than words, they should therefore be processed more fluently. Under these conditions, a larger effect in letters than in words would have been expected. In other words, if we attribute a frequency of 0 per million to pseudoletters and nonwords made of pseudoletters, of 100 to letters and of 10 to words (letters being more frequent than words; New \& Grainger, 2011), then the illusion should be stronger when we compare letters (100) and pseudoletters (0) than when we compare words (10) and nonwords made of pseudoletters (0). Yet our results highlight the opposite pattern. On the other hand, these results could be explained with the IAM. The illusion might be stronger for words than for letters because back-propagation benefits from two levels for words (letter and word units) and only from one level for letters (letter units). Nevertheless, note that the fluency hypothesis and the interactive model are not necessarily mutually exclusive. For instance, the more back-propagation available to guide perception, the more easily a stimulus can be processed, and in this case, the two interpretations cannot be disentangled. Furthermore, if we consider that isolated letters are not processed similarly to letters presented in words, then isolated letters might be less frequent than words, and these results might be compatible with the fluency account hypothesis. Our results cannot firmly disentangle these two hypotheses. Further experiments will be needed in order to address this issue.

Altogether, our results demonstrate that both letters and words are perceived as being taller than mirror stimuli and stimuli made of pseudoletters of the same physical height. This perceptual enhancement of letters and words can be interpreted within the framework of the IAM, as the result of feedback from the letter to the feature level, or from the word to the letter level. Our findings raise the question of whether such perceptual enhancement for letters and words can be generalized to other visual stimuli that receive specific processing, such as faces.

\section{Appendix}

\begin{tabular}{|c|c|c|c|c|c|c|}
\hline Letter & Pseudolette & Mirror & word & Pseudoletters & Mirror & Psevdoword \\
\hline a & $\mathfrak{\Omega}$ & $\mathbb{9}$ & BATEAU & $\lambda \lambda \Gamma \hookleftarrow \lambda \bullet$ & B $\forall L E \forall \cap$ & TEAUBA \\
\hline C & e & G & BUREAU & ג৮dt ג৮ & ВПВЕ $\forall$ Г & REAUB \\
\hline e & 3 & $G$ & CAMION & $\gtrless \lambda \Delta\{1 \times(x$ & CVWIOU & MIONCA \\
\hline $\mathrm{m}$ & $\Psi$ & U & CANAL & $\vartheta \lambda \ltimes \lambda F$ & С ИИマГ & NALCA \\
\hline$r$ & I & I. & GENOU & $\exists+\times \times b$ & СЕИОП & NOUGE \\
\hline $\mathrm{S}$ & B & ¿ & JARDIN & $4 \lambda d \vdash 1 X$ & 1甘BDIИ & DINJAR \\
\hline V & $\lambda$ & $\Lambda$ & LAPIN & $\mathrm{F} \lambda$ 지 & ГӨЬЦИ & PINLA \\
\hline W & It & $M$ & PARFUM & শג৯А৮৫ & b $\forall$ BEกW & FUMPAR \\
\hline Z & $f$ & $\Sigma$ & TIIYAI & 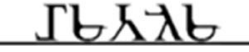 & LI & Y UTA I \\
\hline
\end{tabular}

\section{References}

Bornstein, M. H., Gross, C. G., \& Wolf, J. Z. (1978). Perceptual similarity of mirror images in infancy. Cognition, 6, 89-116.

Cornell, J. M. (1985). Spontaneous mirror-writing in children. Canadian Journal of Psychology, 39, 174-179. doi:10.1037/h0080122
Gattass, R., Sousa, A. P., \& Gross, C. G. (1988). Visuotopic organization and extent of V3 and V4 of the macaque. Journal of Neuroscience, $8,1831-1845$.

Goldinger, S. D., Kleider, H. M., \& Shelley, E. (1999). The marriage of perception and memory: Creating two-way illusions with words and voices. Memory \& Cognition, 27, $328-338$. 
Grainger, J., \& Jacobs, A. M. (1996). Orthographic processing in visual word recognition: A multiple read-out model. Psychological Review, 103, 518-565. doi:10.1037/0033-295X.103.3.518

Jacoby, L. L., Allan, L. G., Collins, J. C., \& Larwill, L. K. (1988). Memory influences subjective experience: Noise judgments. Journal of Experimental Psychology: Learning, Memory, and Cognition, 14, 240-247. doi:10.1037/0278-7393.14.2.240

Jacoby, L. L., \& Dallas, M. (1981). On the relationship between autobiographical memory and perceptual learning. Journal of Experimental Psychology: General, 110, 306-340. doi:10.1037/0096-3445.110.3. 306

Kosslyn, S. M. (1994). Image and brain. Cambridge, MA: MIT Press.

Lupyan, G., Thompson-Schill, S. L., \& Swingley, D. (2010). Conceptual penetration of visual processing. Psychological Science, 21, 682691. doi:10.1177/0956797610366099

Madec, S., Rey, A., Dufau, S., Klein, M., \& Grainger, J. (2012). The time course of visual letter perception. Journal of Cognitive Neuroscience, 24, 1645-1655.

Masson, M. E. J., \& Caldwell, J. I. (1998). Conceptually driven encoding episodes create perceptual misattributions. Acta Psychologica, 98, 183-210.

McClelland, J. L., \& Rumelhart, D. E. (1981). An interactive activation model of context effects in letter perception: I. An account of basic findings. Psychological Review, 88, 375-407. doi:10.1037/0033295X.88.5.375

New, B., \& Grainger, J. (2011). On letter frequency effects. Acta Psychologica, 138, 322-328. doi:10.1016/j.actpsy.2011.07.001

Newsome, W. T., Maunsell, J. H., \& van Essen, D. C. (1986). Ventral posterior visual area of the macaque: Visual topography and areal boundaries. Journal of Comparative Neurology, 252, 139-153.

Olkkonen, M., Hansen, T., \& Gegenfurtner, K. R. (2008). Color appearance of familiar objects: Effects of object shape, texture, and illumination changes. Journal of Vision, 8(5), 13.1-16. doi:10.1167/8.5.13

Reber, R., Winkielman, P., \& Schwarz, N. (1998). Effects of perceptual fluency on affective judgments. Psychological Science, 9, 45-48. doi:10.1111/1467-9280.00008

Reber, R., Zimmermann, T. D., \& Wurtz, P. (2004). Judgments of duration, figure-ground contrast, and size for words and nonwords. Perception \& Psychophysics, 66, 1105-1114.
Reber, R., \& Zupanek, N. (2002). Effects of processing fluency on estimates of probability and frequency. In P. Sedlmeier \& T. Betsch (Eds.), Frequency processing and cognition (pp. 175-188). Oxford, UK: Oxford University Press. doi:10.1093/acprof:oso/ 9780198508632.003 .0011

Reicher, G. M. (1969). Perceptual recognition as a function of meaningfulness of stimulus material. Journal of Experimental Psychology, 81, 275-280. doi:10.1037/h0027768

Reingold, E. M., \& Jolicœur, P. (1993). Perceptual versus postperceptual mediation of visual context effects: Evidence from the lettersuperiority effect. Perception \& Psychophysics, 53, 166-178.

Rockland, K. S., \& Pandya, D. N. (1979). Laminar origins and terminations of cortical connections of the occipital lobe in the rhesus monkey. Brain Research, 179, 3-20.

Rollenhagen, J. E., \& Olson, C. R. (2000). Mirror-image confusion in single neurons of the macaque inferotemporal cortex. Science, 287, 1506-1508.

Schendel, J. D., \& Shaw, P. (1976). A test of the generality of the wordcontext effect. Perception \& Psychophysics, 19, 383-393.

Szwed, M., Dehaene, S., Kleinschmidt, A., Eger, E., Valabrègue, R., Amadon, A., \& Cohen, L. (2011). Specialization for written words over objects in the visual cortex. NeuroImage, 56, 330-344. doi:10. 1016/j.neuroimage.2011.01.073

Tootell, R. B., Silverman, M. S., Switkes, E., \& De Valois, R. L. (1982). Deoxyglucose analysis of retinotopic organization in primate striate cortex. Science, 218, 902-904.

Waenke, M., Schwarz, N., \& Bless, H. (1995). The availability heuristic revisited: Experienced ease of retrieval in mundane frequency estimates. Acta Psychologica, 89, 83-90.

Weisstein, N., \& Harris, C. S. (1974). Visual detection of line segments: An object-superiority effect. Science, 186, 752-755.

Whittlesea, B. W. A., Jacoby, L. L., \& Girard, K. (1990). Illusions of immediate memory: Evidence of an attributional basis for feelings of familiarity and perceptual quality. Journal of Memory and Language, 29, 716-732. doi:10.1016/0749596X(90)90045-2

Williams, A., \& Weisstein, N. (1978). Line segments are perceived better in a coherent context than alone: An object-line effect in visual perception. Memory \& Cognition, 6, 85-90. 